\title{
Espécies Ativas de Oxigênio na Resposta de Defesa de Plantas a Patógenos
}

\author{
Mário Lúcio V. Resende, Sônia M. L. Salgado \& Zuleide M. Chaves \\ Departamento de Fitopatologia, Universidade Federal de Lavras, Cx. Postal 37, Lavras, MG, \\ CEP 37200-000, e-mail: mlucio@ufla.br
}

(Aceito para publicação em 31/01/2003)

Autor para correspondência: Mário Lúcio V. Resende

RESENDE, M.L.V., SALGADO, S.M.L. \& CHAVES, Z.M. Espécies ativas de oxigênio na resposta de defesa de plantas a patógenos. Fitopatologia Brasileira 28:123-130. 2003.

\section{RESUMO}

A explosão oxidativa é uma resposta de defesa da planta após o reconhecimento do patógeno, conduzindo à reação de hipersensibilidade (HR). Esta resposta é devido à geração de espécies ativas de oxigênio (ROS ou EAO's), tais como $\mathrm{H}_{2} \mathrm{O}_{2}, \mathrm{O}_{2}^{-}$, e OH${ }^{-}$As espécies ativas de oxigênio possuem várias funções na resposta de defesa da planta. Peróxido de higrogênio $\left(\mathrm{H}_{2} \mathrm{O}_{2}\right)$ pode ser diretamente tóxico ao patógeno e está envolvido com o fortalecimento da parede celular, uma vez que $\mathrm{o}_{2} \mathrm{O}_{2}$ é necessário para a biossíntese de lignina. Peróxido de hidrogênio atua também como mensageiro secundário, sendo responsável pela ativação da hidrolase do ácido benzóico, enzima responsável pela conversão do ácido benzóico em ácido salicílico. A explosão oxidativa não está confinada somente à HR macroscópica, uma vez que explosões oxidativas secundárias poderão ocorrer nos tecidos distantes, causando micro-HR's e conduzindo à resistência sistêmica adquirida (SAR), a qual é mediada pelo ácido salicílico como um sinal. Portanto, a ocorrência de HR e SAR é dependente da cascata de sinalização derivada da explosão oxidativa, que por sua vez é um evento inicial na resposta da planta contra a invasão do patógeno.

Palavras-chave adicionais: resistência, explosão oxidativa, HR, SAR.

\section{ABSTRACT}

Reactive oxygen species on plant defense responses to pathogens Oxidative burst is a very quick plant defense response after pathogen recognition, leading to hypersensitive reaction (HR). This response is due to generation of reactive oxygen species (ROS), such as $\mathrm{H}_{2} \mathrm{O}_{2}, \mathrm{O}_{2}^{-}$, and $\mathrm{OH}^{-}$. Several roles in plant defense have been proposed for ROS. Hidrogen peroxide $\left(\mathrm{H}_{2} \mathrm{O}_{2}\right)$ apart from being directly toxic to pathogens, is also involved in cell wall strengthening, since it is necessary for lignin biosynthesis. Hidrogen peroxide acts as a second messenger, being responsible for the activation of the benzoic acid 2-hydrolase, enzyme responsible for benzoic acid conversion to salycilic acid. Oxidative burst is not only confined to the macroscopic site of HR, since secondary bursts can occur in distant tissues, causing micro-HR's and leading to systemic acquired resistance (SAR), which is mediated by salycilic acid as a signal. Therefore, occurrence of both HR and SAR are dependent on signaling cascades derived from oxidative burst, as an early event in plant response against pathogen invasion.

\section{INTRODUÇÃO}

As interações planta-patógeno são classificadas em compatíveis (patógeno virulento e hospedeiro suscetível) e incompatíveis (patógeno avirulento e hospedeiro resistente). Nas interações incompatíveis, o sistema de defesa da planta é eficientemente ativado, conduzindo à resistência, mas é tardiamente ativado ou não ativado em interações compatíveis, condicionando a doença. A presença de um gene de resistência, dominante na planta $(R)$ e um gene de avirulência dominante no patógeno (Avr) condiciona a incompatibilidade em interações gene-a-gene.

A infecção por patógenos avirulentos induz uma série de respostas de defesa freqüentemente resultando no colapso localizado de células vegetais conhecido como reação de hipersensibilidade (HR) (Stakawicz et al., 1995). Nessa reação, há a produção de intermediários reativos de oxigênio, conhecidos como 'Reactive Oxygen Intermediates' (ROI) ou 'Reactive Oxygen Species' (ROS), ou ainda 'Espécies Ativas de Oxigênio' (EAO's), incluindo o $\mathrm{O}_{2}{ }^{--}, \mathrm{H}_{2} \mathrm{O}_{2}$ e OH• (Hegedus et al., 2001).

A explosão oxidativa participa de um sistema integrado e amplificado de sinalização, que envolve o ácido salicílico e cálcio $\left(\mathrm{Ca}^{2+}\right)$ citosólico no disparo dos mecanismos de defesa (Lamb \& Dixon, 1997). O desenvolvimento da HR, inicialmente desencadeado pela presença de espécies ativas de oxigênio, promove o estabelecimento gradual da resistência sistêmica adquirida (SAR) (Alvarez et al., 1998). 
Na presente revisão, procurou-se abordar aspectos da explosão oxidativa como a química da produção de espécies ativas de oxigênio, EAO's e a patogênese em plantas, mecanismos envolvidos na explosão oxidativa, funções das EAO's na planta e sua quantificação durante a interação planta-patógeno.

\section{QUÍMICA DA PRODUÇÃO DE ESPÉCIES ATIVAS DE OXIGÊNIO}

Simplificadamente, a partir do $\mathrm{O}_{2}$, os agentes de explosão oxidativa são:

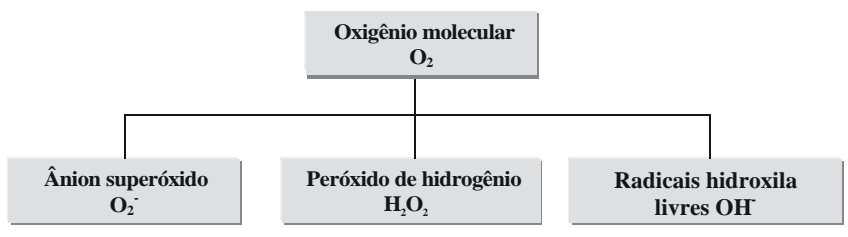

$\mathrm{O}$ oxigênio molecular $\left(\mathrm{O}_{2}\right)$ é relativamente não reativo e não tóxico, devido a estrutura estável dos elétrons na sua camada externa. Entretanto, alterações na distribuição dos elétrons podem provocar a sua ativação e influenciar os sistemas biológicos. As EAO's podem ser geradas dentro das plantas como resultado da excitação ou um "leve toque" no elétron externo, formando oxigênio simples $\left({ }^{1} \mathrm{O}_{2}\right)$ ou de uma sucessiva adição de elétrons ao oxigênio molecular produzindo $\mathrm{O}_{2}{ }^{--}, \mathrm{H}_{2} \mathrm{O}_{2}$ e $\mathrm{OH} \cdot$ (Figura 1). Essas moléculas, descritas a seguir, são consideradas "ativas" porque não necessitam da entrada de energia para reagir com outras moléculas.

Superóxido $\left(\mathrm{O}_{2}{ }^{--}\right)$: pode ser produzido na planta por meio de vários mecanismos, inclusive pela ativação de NADPH-oxidases/sintases ligadas à membrana, peroxidases (POX) da parede celular, lipoxigenases (LOX) e como resultado da transferência de elétrons da mitocôndria ou do cloroplasto. Normalmente, oxida várias moléculas orgânicas, como o ascorbato, ou como redutor de metais como $\mathrm{Fe}^{3+}$, nas reações de Haber-Weiss ou Fenton (Breusegem et al., 2001).

$$
\begin{aligned}
& \text { Reação de Fenton ou Haber -Weiss } \\
& \text { I) } \mathrm{Fe}^{3+}+\mathrm{O}_{2} \cdot \cdot \longrightarrow \\
& \text { II) } \mathrm{Fe}^{2+}+\mathrm{O}_{2}
\end{aligned}
$$

$$
\text { Reação geral: } \mathrm{O}_{2}^{\cdot^{-}}+\mathrm{H}_{2} \mathrm{O}_{2} \rightarrow \mathrm{OH}^{-}+\mathrm{OH}^{-}+\mathrm{O}_{2}
$$

Peróxido de hidrogênio $\left(\mathrm{H}_{2} \mathrm{O}_{2}\right)$ : a maioria do $\mathrm{H}_{2} \mathrm{O}_{2}$ celular surge da dismutação do $\mathrm{O}_{2}{ }^{-}$- catalisada pela SOD (Tabela 1). Peróxido de hidrogênio é um oxidante relativamente estável e ausente de carga, o que pode facilitar a passagem através da camada bilipídica da membrana celular. Essa capacidade de difundir-se rapidamente através da membrana celular favorece a rápida elicitação da resposta vegetal (Apostol et al., 1989).

Radical hidroxila $(\mathbf{O H})$ : embora os radicais hidroxila tenham meia-vida curta $(<1 \mu \mathrm{s})$, são radicais potencialmente

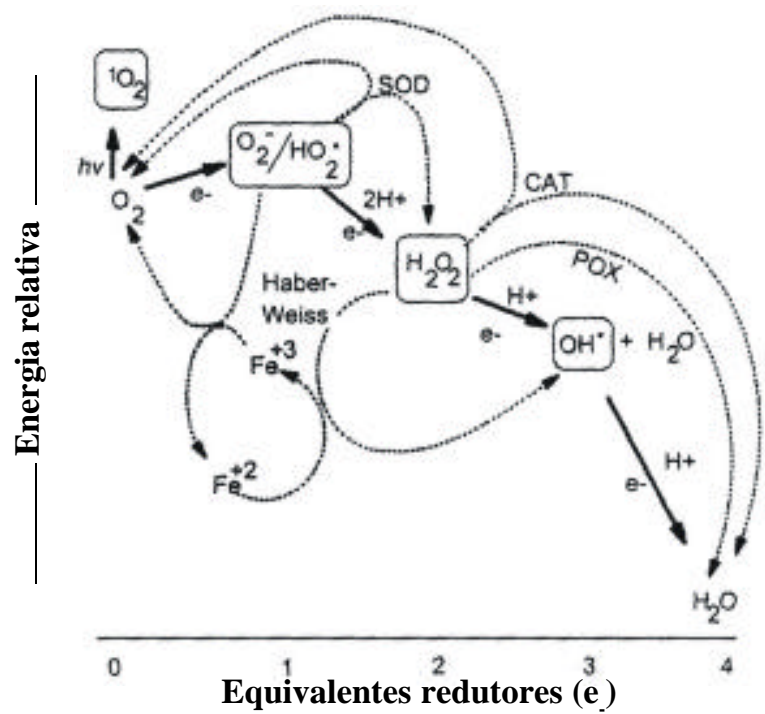

FIG. 1 - Fluxo de elétrons durante a explosão oxidativa: espécies ativas de oxigênio (EAO's) derivadas de $\mathrm{O}_{2}$, vias de detoxificação (limpeza) e interconversões em plantas (adaptado de Baker \& Orlandi, 1999).

fortes e com alta afinidade à biomoléculas no seu sítio de produção (Halliwell \& Gutteridge, 1989), o que dificulta o estudo desses radicais.

Oxigênio simples $\left({ }^{1} \mathrm{O}_{2}\right)$ : semelhante aos radicais hidroxila, os ${ }^{1} \mathrm{O}_{2}$ têm aproximadamente $2 \mu$ s de vida e são altamente destrutivos, reagindo com a maioria das moléculas biológicas (Foyer et al., 1994), porém a maioria dos danos são próximos aos sítios onde são produzidos. São predominantemente gerados nos cloroplastos, através da transferência de energia de uma clorofila foto-excitada para o elétron do oxigênio molecular. ${ }^{1}$ Oxigênio simples reage facilmente com ligações duplas e têm alta afinidade com "dienos" na membrana e aminoácidos específicos como histidina, metionina, triptofano e cisteína.

$\mathrm{O}$ acúmulo de $\mathrm{H}_{2} \mathrm{O}_{2}$ pode depender de duas etapas consecutivas: redução do $\mathrm{O}_{2}$ molecular a $\mathrm{O}_{2}^{-}$seguida pela dismutação espontânea ou catalisada de $\mathrm{O}_{2}{ }^{-} \mathrm{a} \mathrm{H}_{2} \mathrm{O}_{2}$. A enzima SOD catalisa uma conversão altamente eficiente de $\mathrm{O}_{2}-\% \cdot \mathrm{HO}_{2}$ a $\mathrm{H}_{2} \mathrm{O}_{2}$, numa velocidade $10^{10}$ vezes maior que na reação espontânea.

\section{EAO's E A PATOGÊNESE EM PLANTAS}

Os primeiros estudos enfocando as EAO's na defesa vegetal, foram realizados por Doke (1983), na década de 80, muito embora a produção de radicais de oxigênio já tivesse sido constatada em células do sistema imunológico humano (Baldridge \& Gerard, 1933). Doke (1983) e Doke \& Ohashi (1988) publicaram os primeiros relatos da produção de $\mathrm{O}_{2}^{-}$ nas interações incompatíveis nos patossistemas batata (Solanum tuberosum L.)-Phytophthora infestans (Mont.) de Bary e fumo (Nicotiana tabacum L.) -vírus do mosaico do 
Espécies ativas de oxigênio na resposta de defesa de plantas...

TABELA 1 - Equações químicas ilustrando as principais enzimas chaves catalisando a formação e degradação de espécies ativas de oxigênio (EAO's) em plantas

\begin{tabular}{ll}
\hline Superóxido dismutase (SOD) & $\mathrm{H}_{2} \mathrm{O}_{2}+\mathrm{O}_{2}{ }^{--}+\mathrm{H}^{+} \rightarrow \mathrm{H}_{2} \mathrm{O}_{2}+\mathrm{O}_{2}$ \\
& $\mathrm{O}_{2}{ }^{-}+\mathrm{O}_{2}{ }^{-}+2 \mathrm{H}+\rightarrow \mathrm{H}_{2} \mathrm{O}_{2}+\mathrm{O}_{2}$ \\
\hline Ascorbato Peroxidase (APX) & $\mathrm{APX}+\mathrm{H}_{2} \mathrm{O}_{2} \rightarrow$ Composto $\mathrm{I}+\mathrm{H}_{2} \mathrm{O}$ \\
& Composto I + Ascorbato $\rightarrow$ Composto II $+\mathrm{MDA}^{\cdot *}$ \\
& Composto II + Ascorbato $\rightarrow$ APX $+\mathrm{MDA}^{\cdot}+\mathrm{H}_{2} \mathrm{O}$ \\
\hline Catalase & $\mathrm{H}_{2} \mathrm{O}_{2}+\mathrm{H}_{2} \mathrm{O}_{2} \rightarrow 2 \mathrm{H}_{2} \mathrm{O}+\mathrm{O}_{2}$ \\
\hline
\end{tabular}

$\mathrm{MDA}^{\cdot(*)}$ : Radical monodehidroascorbato

fumo (Tobacco mosaic virus, TMV).

As EAO's ocorrem durante o contato inicial entre o patógeno e a célula vegetal mas podem também ser produzidas e apresentar um papel sutil nos estádios posteriores da patogênese. Durante a interação planta-patógeno a produção de EAO's acontece em três fases: na fase I ocorre o reconhecimento dos elicitores provenientes do patógeno, que podem ser carboidratos, proteínas ou porções de glicoproteínas. Esse reconhecimento dispara os eventos de transdução de sinais. Durante a fase II são iniciados vários processos relacionados à defesa, mas não identificados por sintomas visíveis. Os processos ou vias metabólicas dessa fase são resultantes do reconhecimento durante a fase I, e nesses processos de defesa incluem-se aumento de antioxidantes, ação de lipoxigenases, a HR, produção de fitoalexinas, lignificação e SAR. A fase III compreende o processo de evolução da patogênese levando ao desenvolvimento de sintomas visíveis. A diferenciação da patogênese em três fases distintas é apenas um artifício para compreensão de como ocorrem tais processos. Na natureza, dependendo das interações, ocorrerá uma sobreposição dos eventos fisiológicos (Baker \& Orlandi, 1999).

\section{MECANISMOS ENVOLVIDOS NA EXPLOSÃO OXIDATIVA}

\section{Mecanismos indutores da produção de EAO's}

Injúrias no tecido vegetal e processos oxidativos normais da célula são provavelmente responsáveis pela geração de $\mathrm{O}_{2}^{-}$. Durante o transporte de elétrons $\left(\mathrm{e}^{-}\right)$nos cloroplastos e mitocôndrias, muitos desses e- são perdidos, e então captados pelo $\mathrm{O}_{2}$ formando $\mathrm{O}_{2}{ }^{-}$(Leshem, 1988, citado por Goodman \& Novacky, 1994).

Fatores abióticos tais como UV B (280 a $320 \mathrm{~nm})$, extremos de temperatura, poluentes, estresse osmótico e mecânico, podem aumentar a produção de EAO's. Contudo, os elicitores mais efetivos são macromoléculas derivadas do patógeno que se ligam a receptores na superfície da célula vegetal (Allan \& Fluhr, 1997).

Segundo Hammond-Kosack \& Jones (1996), provavelmente, o ozônio $\left(\mathrm{O}_{3}\right)$ ou UV-B, sinalizadores não específicos, induzem o acúmulo de EAO's. Isso foi confirmado recentemente por Wohlgemuth et al. (2002) ao verificarem que o $\mathrm{O}$ induziu a produção e acúmulo de $\mathrm{H}_{2} \mathrm{O}_{2}$ em plantas de fumo ${ }^{3}$ e tomate (Lycopersicon esculentum Mill.), e $\mathrm{H}_{2} \mathrm{O}_{2} \mathrm{e}$ $\mathrm{O}_{2}{ }^{-}$em Arabidopsis sp. Neste estudo, a geração e acúmulo de
$\mathrm{H}_{2} \mathrm{O}_{2}$ e/ou $\mathrm{O}_{2}^{-}$foi dependente da espécie e cultivar da planta, apesar de ambas EAO's estarem envolvidas na indução da morte celular.

Duas fases de indução de EAO's por elicitores fúngicos e bacterianos tem sido avaliadas em culturas de células vegetais. A fase I corresponde a aquela de resposta muito rápida (poucos minutos) (Baker \& Orlandi, 1995). Embora a produção de EAO's na fase I, possivelmente envolva uma interação elicitor-receptor, as respostas nem sempre são correlacionadas com resistência a fitodoenças, podendo também ocorrer em interações compatíveis. $\mathrm{Na} 2^{\mathrm{a}}$ fase de produção de espécies ativas de oxigênio ocorre uma explosão mais forte e prolongada, que está diretamente correlacionada com a resistência da planta ao patógeno, provocando a morte localizada de células (HR) e, portanto, essa fase é característica das interações incompatíveis (Dangl et al., 2000).

Elicitores derivados do patógeno provocam uma biossíntese muito rápida de EAO's (menos de 5 min), que requer $\mathrm{Ca}^{++}$externo e a ativação de canais de íons. Contrariamente, bactérias avirulentas provocam uma pequena explosão oxidativa inicial rápida e, após 2 a 4 h, uma explosão oxidativa massiva. Este atraso reflete o tempo requerido para o sinal da bactéria avirulenta ser liberado para as células da planta e processado para uma forma que possa elicitar o mecanismo de reconhecimento (Figura 2) (Keppler \& Baker, 1989; Keppler et al. 1989; Baker et al, 1991).

$\mathrm{Na}$ interação entre uma raça incompatível de Phytophthora nicotianae Breda de Hann e células de fumo, a produção de $\mathrm{H}_{2} \mathrm{O}_{2}$ ocorreu em sucessivas explosões oxidativas, verificadas entre 0 e 2 h após a inoculação. Entretanto, uma explosão oxidativa mais intensa ocorreu no período de 8 a 10 h após a inoculação (Able et al., 2000).

A explosão oxidativa envolve a ativação de componentes de oxidases pré-existentes mais do que a síntese de novo do maquinário de explosão oxidativa. O mecanismo que as plantas possuem para gerar $\mathrm{O}_{2}{ }^{-}$a partir do oxigênio molecular, possivelmente envolve uma NADPH oxidase associada à membrana. Há indicações de que plantas e mamíferos geram

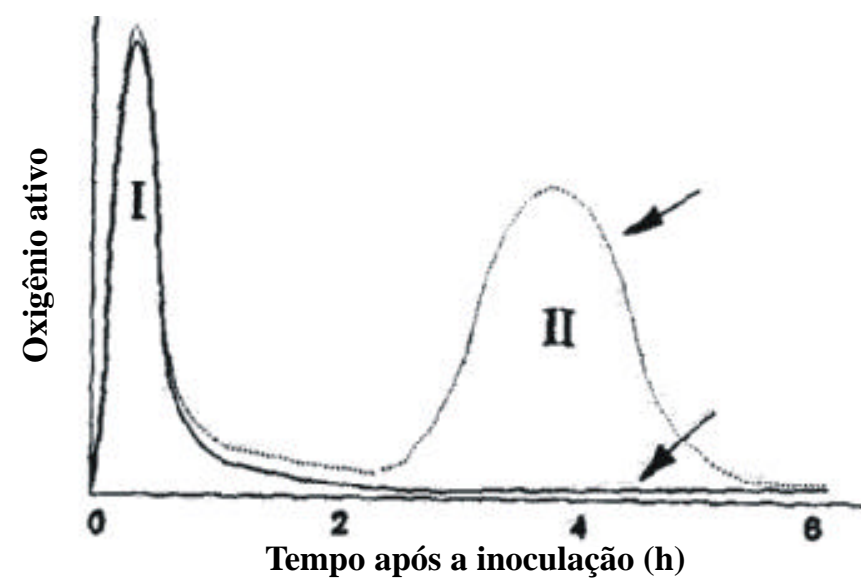

FIG. 2 - Fases da produção de EAO's na interação planta-bactéria (adaptado de Baker \& Orlandi, 1995). 


\section{M.L.V. Resende et al.}

EAO's de maneira similar durante as respostas de defesa. Entretanto, a presença de um motivo citoplasmático no qual o cálcio se liga a NADPH oxidase vegetal, sugere a possibilidade de regulação direta da atividade dessa oxidase, através da percepção de trocas em concentrações subcelulares de cálcio, em vez da montagem de oxidases citoplasmáticas adicionais, como ocorre em sistemas de defesa de mamíferos (Hammond-Kosack \& Jones, 2000). Exemplificando, componentes citosólicos pré-formados como o $\mathrm{Ca}^{++}$, ATP e uma etapa de fosforilação, contribuíram para aumentar a atividade in vitro da NADPH oxidase associada à membrana plasmática de células de tubérculos de batata infetados por $P$. infestans (Allan \& Fluhr,1997) .

Culturas de células de feijoeiro (Phaseolus vulgaris L.), testadas com dois diferentes tipos de elicitores, mostraram um rápido aumento na absorção de oxigênio, seguido pela produção transitória de $\mathrm{H}_{2} \mathrm{O}_{2}$ e aumento na atividade catalítica da peroxidase. Uma alcalinização transitória do apoplasto, pH 7,0-7,2, foi necessária para a geração de $\mathrm{H}_{2} \mathrm{O}_{2}$ nesse sistema. Nenhuma dessas rotas alternativas foram inibidas por difenilenoiodonium, levando a crer que a produção de EAO's durante as interações incompatíveis poderia ocorrer por mecanismos divergentes em diferentes espécies vegetais e a contribuição de cada mecanismo para a explosão oxidativa poderia variar de acordo com a espécie em questão (Hammond-Kosack \& Jones, 1996).

\section{Mecanismos celulares para inibição das EAO}

As EAO's ocorrem normalmente no metabolismo celular, porém, quando acumuladas tornam-se tóxicas à célula. $\mathrm{O} \mathrm{H}_{2} \mathrm{O}_{2}$ sobrevive no citoplasma da célula em concentrações suficientes para alcançar o núcleo da célula vegetal ou do patógeno, podendo reagir com íons metálicos intracelulares. Dessa forma, embora moderadamente reativas por elas próprias, muito do prejuízo celular causado por $\mathrm{H}_{2} \mathrm{O}_{2}$ e $\mathrm{O}_{2}^{-}$ resulta da conversão dessas moléculas para espécies ainda mais reativas. Exemplo disso é a conversão do $\mathrm{H}_{2} \mathrm{O}_{2}$, na presença de $\mathrm{Fe}^{2+}$, para $\mathrm{OH}^{-}$, extremamente tóxico. Esses radicais podem reagir com proteínas e assim reduzir a atividade de enzimas, reagir com lipídios e aumentar a permeabilidade de membranas e ainda reagir com o DNA causando mutações (Moller, 2001). Portanto, como o acúmulo de EAO's pode resultar em prejuízos consideráveis, a célula dispõe de vários mecanismos para detoxificar eficientemente essas espécies ativas de oxigênio. Esses mecanismos de proteção, foram desenvolvidos pelas plantas durante o processo de evolução, para controlar os níveis dessas moléculas e anular essa toxicidade. Moléculas antioxidantes, enzimas simples, e um sistema mais complexo de detoxificação, podem estar envolvidos na proteção celular contra EAO's acumuladas. Conhecidos como "scavengers", várias enzimas reguladoras (Tabela 1) impedem a ação tóxica das EAO's à célula vegetal.

Superóxido dismutases: as SOD's são enzimas catalisadoras da dismutação do $\mathrm{O}_{2}^{\cdot-}$ e $\mathrm{HO}_{2}^{+} \mathrm{a} \mathrm{H}_{2} \mathrm{O}_{2}$, e podem estar ligadas a um metal $(\mathrm{Cu} / \mathrm{Zn}, \mathrm{Mn}$ e Fe). As plantas, normalmente, têm $\mathrm{Cu} / \mathrm{Zn}$-SOD no citosol, $\mathrm{Cu} / \mathrm{Zn}$ e/ou FeSOD no cloroplasto e Mn-SOD na mitocôndria. As SOD's são consideradas importantes agentes antioxidantes porém, em elevadas concentrações nas células animais e bacterianas, podem induzir disfunções e morte celular (Baker \& Orlandi, 1995).

Ciclo do ascorbato/glutationa: principal sistema de remoção das EAO's nos cloroplastos. Nesse ciclo são empregadas quatro enzimas: ascorbato peroxidase (APX), dehidroascorbato redutase (DHA), monodehidroascorbato redutase (MDA) e glutationa redutase. $\mathrm{O} \mathrm{H}_{2} \mathrm{O}_{2}$ pode ser reduzido e removido pela APX através do ascorbato como redutor, formando o radical monodehidroascorbato (MDA•) (Yoshimura et al., 2000). Esse por sua vez, irá dismutar para dehidroascorbato (DHA) e ascorbato.

Catalase: são enzimas que convertem o $\mathrm{H}_{2} \mathrm{O}_{2}$ em $\mathrm{H}_{2} \mathrm{O}$ e $\mathrm{O}_{2}$. As plantas possuem várias isoformas de catalase, as quais estão presentes nos peroxissomas e glioxissomas. São as principais enzimas de detoxificação do $\mathrm{H}_{2} \mathrm{O}_{2}$ em plantas e podem dismutar diretamente $\mathrm{o}_{2} \mathrm{O}_{2}$ ou oxidar substratos, tais como metanol, etanol, formaldeído e ácido fórmico. As catalases podem ser dividas em três classes: catalases da classe 1 removem $\mathrm{o}_{2} \mathrm{O}_{2}$ produzido durante a fotorespiração em tecidos fotossintéticos; catalases da classe 2 são produzidas em tecidos vasculares e podem exercer uma função de lignificação mas, sua exata função biológica permanece desconhecida; e na classe 3 estão as catalases presentes abundantemente em sementes e plantas jovens, e cuja atividade está relacionada à remoção do $\mathrm{H}_{2} \mathrm{O}_{2}$ produzido durante a degradação dos ácidos graxos no glioxissoma. As catalases funcionam então como canal de limpeza do $\mathrm{H}_{2} \mathrm{O}_{2}$ celular (Breusegem et al. 2001). Em soja [Glycine max (L.) Merril], Dixon et al. (1994) verificaram que a adição da catalase ou ácido ascórbico, potentes antioxidantes, bloqueou o acúmulo da fitoalexina gliceolina elicitada por Verticillium dahliae Kleb. Pelo lado do patógeno, possivelmente a catalase seja uma forma de defesa enzimática de alguns patógenos contra as EAO's do hospedeiro (Garre et al., 1998), isso porque essas enzimas localizadas nos peroxissomos de muitos organismos, incluindo os fungos, quando aplicadas na célula vegetal, impedem a influência positiva do gene da glucose oxidase na resistência do hospedeiro e efetivamente inibem a explosão oxidativa, a produção de fitoalexinas e a ação de $\mathrm{H}_{2} \mathrm{O}_{2}$ na morte celular programada durante a HR.

$\beta$-caroteno: é um eficiente agente de detoxificação de ${ }^{1} \mathrm{O}_{2}$. Os carotenóides participam do sistema de antenas dos cloroplastos, na absorção de luz e transferência de energia para os centros das reações. Entretanto, os carotenóides também podem dissipar energia durante o estresse fotoxidativo (Baker \& Orlandi, 1999).

As EAO's induzidas por elicitores fúngicos e bacterianos durante a fase inicial da explosão oxidativa, têm sido especificamente inibidas por difenilenoiodonium (DPI), 
Espécies ativas de oxigênio na resposta de defesa de plantas...

inibidores do influxo de cálcio e inibidores de quinases (Baker \& Orlandi, 1995; Hammond-Kosack \& Jones, 1996).

Nas mitocôndrias, principal sítio de produção de EAO's na célula vegetal, existem várias enzimas para detoxificação de EAO's. Recentemente a thioredoxina, pequena proteína (12 - $14 \mathrm{kDa}$ ) com duas cisteínas no sítio ativo, tem sido apontada como possível agente de detoxificação de EAO's (Moller, 2001). No entanto, esse autor considera que o sistema celular de detoxificação de EAO's está pouco esclarecido.

\section{FUNÇÕES DAS EAO's NA PLANTA}

A rápida geração e acúmulo de espécies ativas de oxigênio, desencadeadas pela explosão oxidativa após a percepção dos sinais de avirulência do patógeno, atuam com diferentes funções de defesa. Dentre as várias funções das EAO's na defesa vegetal, podemos citar o efeito tóxico direto de $\mathrm{H}_{2} \mathrm{O}_{2}$ ao patógeno, agindo como um agente antifúngico e antibacteriano (Sutherland, 1991; Allan \& Fluhr, 1997). O efeito antimicrobiano direto das EAO's numa dada interação planta-patógeno, depende das concentrações das EAO's e da sensibilidade do patógeno a essas concentrações (Medhy et al. 1996). Para atuar como antibiótico efetivo na resposta de defesa vegetal, a concentração de $\mathrm{H}_{2} \mathrm{O}_{2}$ no sítio de infecção deve ser alta o bastante para servir como agente microbicida (Medhy et al. 1996). Concentrações micromolares de $\mathrm{H}_{2} \mathrm{O}_{2}$ inibiram a germinação de esporo de vários fungos patogênicos (Peng \& Kúc, 1992). $\mathrm{O} \mathrm{H}_{2} \mathrm{O}_{2}$ a 0,1 mM inibiu completamente o crescimento de Erwinia carotovora ssp. carotovora (Jones) Bergey, Harrison, Breed, Hammer \& Huntoon e mais de $95 \%$ do crescimento de $P$. infestans (Wu et al. 1995). Entretanto, os estudos da atuação do $\mathrm{H}_{2} \mathrm{O}_{2}$ como agente redutor da viabilidade do patógeno, são dificultados pelas várias funções exercidas pelo $\mathrm{H}_{2} \mathrm{O}_{2}$ na célula vegetal (Medhy et al. 1996).

Além da atuação no complexo e integrado sistema de sinalização celular que culminará na ativação da expressão dos genes de defesa (Figura 3), $\mathrm{o}_{2} \mathrm{O}_{2}$ participa do cruzamento oxidativo ('cross-linking') de proteínas da parede celular formando, com a matriz de polissacarídeos, um grande polímero de várias glicoproteínas ricas em hidroxiprolina, reforçando estruturalmente a parede celular. $\mathrm{O} \mathrm{H}_{2} \mathrm{O}_{2}$ também atua como importante substrato das peroxidases e por conseguinte dispara a química de lignificação, com formação de precursores de polímeros de lignina, via atividade da POX (Alvarez et al., 1998).

$\mathrm{Na}$ sinalização para respostas de defesa da planta ao patógeno, $\mathrm{o}_{2} \mathrm{O}_{2}$ é o candidato mais atrativo dentre as EAO's, por causa da sua vida relativamente longa e alta permeabilidade através das membranas. Como $\mathrm{O}_{2} \mathrm{H}_{2} \mathrm{O}_{2}$ não possui elétron pareado, pode atravessar membranas biológicas, nas quais as espécies $\mathrm{O}_{2}^{-}$atravessam lentamente. Desse modo, após o reconhecimento do patógeno avirulento seguido da explosão oxidativa e seus intermediários reativos, ocorre indução de genes de defesa e morte celular, onde $\mathrm{o}_{2} \mathrm{O}_{2}$ age como um sinal para indução de genes de proteção celular nas células vizinhas para restringir o desenvolvimento da lesão (HR), que é, então, acompanhada pelo desenvolvimento de uma resistência sistêmica adquirida (SAR). Essa reação sistêmica de defesa é induzida pela explosão oxidativa no sítio de inoculação (local primário), e pelas subsequentes microexplosões secundárias em folhas distantes, que por sua vez são necessárias para o estabelecimento da SAR. Isso foi comprovado por Alvarez et al. (1998), após a inoculação da bactéria Pseudomonas syringae pv. tomato (Okabe) Young, Dye \& Wilkie ( $\underline{\text { Pst }})$, contendo o gene de avirulência avrRpt ${ }_{2}$, em folhas de Arabidopsis thaliana (L.) Heynh ecotipo Col-0, possuidora do gene de resistência $R p s_{2}$. A bactéria causou uma HR macroscópica no sítio de inoculação, e o desenvolvimento de resistência em folhas não inoculadas (secundárias). Assim como ocorre com os genes das proteínas relacionadas à patogênese (PRPs) em outros sistemas $\mathrm{SAR}, \mathrm{a}$ transcrição e acúmulo de PR-2 ocorreu em folhas secundárias, aproximadamente dois dias após a inoculação da raça avirulenta de Pst nas folhas primárias. Níveis máximos de PR-2 ocorreram após cerca de quatro dias da inoculação (Alvarez et al., 1998).

$\mathrm{Na} \mathrm{SAR}, \mathrm{o}_{2} \mathrm{O}_{2}$ aumenta a atividade da enzima ácido benzóico 2-hidrolase, requerida para a biossíntese do ácido salicílico, potente sinalizador para a ocorrência desse tipo de resistência induzida. Martinez et al. (2000) verificaram que a acumulação sistêmica de ácido salicílico, emitido aproximadamente $3 \mathrm{~h}$ após inoculação de Xanthomonas campestris pv. malvacearum (Smith) Dye em cotilédones de algodão (Gossypium hirsutum L.) cv. Reba B50, estava associado com a explosão oxidativa. Existe uma forte probabilidade de que a geração de EAO's conduziria a uma alteração no balanço redox, e este por sua vez poderia também regular a estabilidade de mRNAs específicos, o que culminaria com a tradução de genes de defesa (Figura 3).

A explosão oxidativa é necessária mas não suficiente para disparar a morte celular (HR). Dados recentes citados por Delledonne et al. (2001) indicam que o óxido nítrico (NO) coopera com as EAO's na ativação da HR, então, aparentemente o NO possui um efeito sinergístico com o $\mathrm{H}_{2} \mathrm{O}_{2}$, na indução de HR.

\section{QUANTIFICAÇÃO DE EAO'S DURANTE A INTERAÇÃ̂O PLANTA-PATÓGENO}

A detecção e quantificação de EAO's em sistemas biológicos é particularmente difícil devido à rápida destruição e detoxificação ('scavenging') desses radicais. Além disso, as EAO's não podem ser medidas diretamente por métodos espectrofotométricos ou HPLC, normalmente aplicados ao estudo de compostos de carbono. Por isso, a maioria das técnicas de detecção de EAO's baseia-se na oxidação ou redução de certos compostos pelas EAO's. A dificuldade de monitoramento das espécies ativas de oxigênio em células vegetais, deve-se ao fato de que muitas são de vida curta e sujeitas aos mecanismos antioxidantes celulares tais como SOD, peroxidases, ciclo do ascorbato/glutationa e catalase. 
M.L.V. Resende et al.

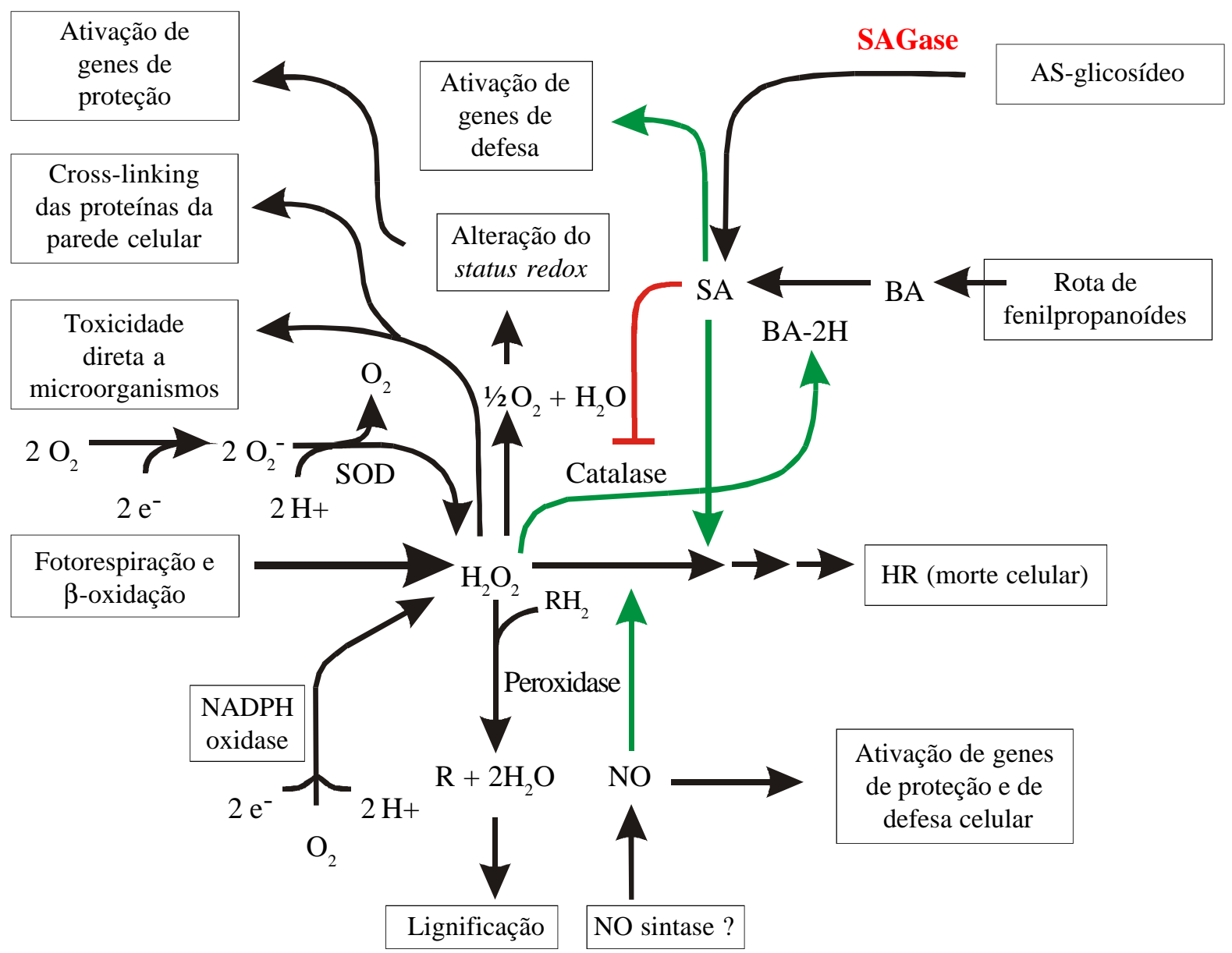

FIG. 3 - Interconexões do $\mathrm{H}_{2} \mathrm{O}_{2}$, óxido nítrico (NO) e ácido salicílico (AS) para a ativação e coordenação das múltiplas reações de defesa das plantas (adaptado de Hammond-Kosack \& Jones, 2000). SOD (superóxido dismutase), SAGase (AS glicosiltransferase) e BA-2H (ácido benzóico 2-hidrolase).

Vários métodos têm sido empregados para monitorar EAO's em tecidos vegetais (Tabela 2). As aplicações, vantagens e desvantagens desses métodos, bem como os cuidados que devem ser tomados na interpretação dos resultados, devem ser considerados. O método da quimioluminescência facilita os estudos que enfocam a produção e detoxificação de EAO's durante as interações incompatíveis planta-bactéria (Baker \& Orlandi, 1995). Delledonne et al. (2001) avaliaram o acúmulo de $\mathrm{H}_{2} \mathrm{O}_{2}$ por fluorescência em escopoletina, e de $\mathrm{O}_{2}^{-}$ pelo monitoramento do citocromo $\mathrm{C}$ e tetrazólio através da análise de absorbância.

O método comumente usado para medir a produção de $\mathrm{O}_{2}{ }^{-}$é a oxidação de epinefrina para formar adrenocromo. Para se medir $\mathrm{H}_{2} \mathrm{O}_{2}$, o mais comum é utilizar uma peroxidase e um substrato oxidável como escopoletina (Moller, 2001). Pelo método da espectroscopia de ressonância magnética de elétrons, Fodor et al. (2001) verificaram a produção de EAO's induzida pelo TMV. A fim de localizar o $\mathrm{H}_{2} \mathrm{O}_{2}$ na célula, Rodriguez et al. (2002) empregaram o método da microscopia eletrônica. Diante disso, verifica-se que são vários os métodos empregados para detectar e/ou monitorar EAO's, e a escolha do método vai depender principalmente do tipo de molécula que se pretende avaliar.

\section{CONSIDERAÇÕES FINAIS}

A explosão oxidativa é uma das respostas mais rápidas de defesa da planta após o reconhecimento do patógeno. Essa resposta corresponde à geração de espécies ativas de oxigênio $\left(\mathrm{H}_{2} \mathrm{O}_{2}, \mathrm{O}_{2}^{-}, \mathrm{OH}^{-}\right)$. São recentes os estudos de detecção e monitoramento destas espécies de oxigênio, devido a grande variedade de formas e intermediários, além da alta taxa de reatividade química envolvida nessas reações, dificultando os estudos. Existem evidências de que $\mathrm{H}_{2} \mathrm{O}_{2}$ está envolvido em muitos mecanismos de resistência da planta, atuando no reforço da parede celular, pela ligação cruzada de proteínas estruturais ou fenólicos, formando uma barreira mecânica efetiva. O peróxido de hidrogênio, no apoplasto da célula hospedeira, pode agir diretamente como um agente antimicrobiano. No entanto, dificilmente esse efeito é quantificado in vivo, em virtude das várias outras funções do $\mathrm{H}_{2} \mathrm{O}_{2}$, atuando, por exemplo, como mensageiro secundário na cascata de transdução de sinais para ativação de genes de defesa e de proteção celular. Assim, as EAO's em geral, são apontadas 
Espécies ativas de oxigênio na resposta de defesa de plantas...

TABELA 2 - Métodos de detecção de espécies ativas de oxigênio (EAO's) em plantas (adaptado de Baker \& Orlandi, 1999)

\begin{tabular}{lc}
\hline \hline Método de deteç̧ão & Sonda química \\
\hline Macroscópico/microscópico & $\begin{array}{c}\text { Nitroblue tetrazólio } \\
\text { Amido/iodeto de potássio } \\
\text { Cloreto de titânio }\end{array}$ \\
\hline Espectrofotométrico & $\begin{array}{c}\text { Nitroblue tetrazólio } \\
\text { Citocromo C } \\
\end{array}$ \\
\hline Fluorescente & Epinefrina \\
\hline Quimioluminescente & Piranina \\
& Escopoletina \\
\hline Espectroscopia de Ressonância & Luminol \\
Magnética de Elétrons & Luciginena \\
& DMPO \\
\hline
\end{tabular}

Luminol = 5-amino-2,3-diidro-1,4-phthalazinediona

$\mathrm{DMPO}=5,5$ '-dimetil-1-oxo-1-pirrolina

4-POBN = 4-piridil 1-oxo N-tertibutilnitrona

como intermediárias na complexa malha de sinalização para as respostas de resistência local (HR) e sistêmica (SAR).

A explosão oxidativa não está confinada à reação macroscópica de HR no sítio de inoculação, pois repetidas explosões secundárias ocorrem em sítios discretos em tecidos distantes, provocando micro-HRs e reação sistêmica (SAR). O papel do $\mathrm{NO}$ como molécula sinérgica ao $\mathrm{H}_{2} \mathrm{O}_{2}$ na $\mathrm{HR}$, carece de investigação. Atualmente é grande a busca por uma NO sintase em plantas, enzima já detectada em células animais. Também se investiga o papel do ácido salicílico, cuja síntese é estimulada por $\mathrm{H}_{2} \mathrm{O}_{2}$, como uma dos sinais que translocam, levando a mensagem da HR para a ativação da SAR.

Com a recente clonagem de vários genes de resistência (R), que geralmente codificam os receptores do sinal de avirulência em interações gene-a-gene, existe um grande interesse na compreensão dos processos envolvidos na explosão oxidativa, como um dos eventos iniciais após o reconhecimento do patógeno pelo hospedeiro. Tais estudos poderão ser aprofundados à medida que as técnicas disponíveis para detecção das EAO's tornarem-se rotineiras em laboratórios de fisiopatologia vegetal e que novas técnicas para detecção in situ sejam também desenvolvidas, acopladas à microscopia eletrônica de transmissão.

\section{LITERATURA CITADA}

ABLE, A.J., GUEST, D.I. \& SUTHERLAND, M.W. Hydrogen peroxide yields during the incompatible interaction of tobacco suspension cells inoculated with Phytophthora nicotianae. Plant Physiology 124:899-910. 2000.

ALLAN, A.C. \& FLUHR, R. Two distinct sources of elicited reactive oxygen species in tobacco epidermal cells. Plant Cell 9:1559-1572. 1997.

ALVAREZ, M.E., PENNELL, R.I., MEIJER, P.J., ISHIKAWA, A., DIXON, R.A. \& LAMB, C. Reactive oxygen intermediates mediate a systemic signal network in the establishment of plant immunity. Cell 92:1-20. 1998.
APOSTOL, I., HEINSTEIN, P.F. \& LOW, P.S. Rapid stimulation of an oxidative burst during elicitation of cultured plant cells. Plant Physiology 90:109-116. 1989.

BAKER, C.J. \& ORLANDI, E.W. Active oxygen and pathogenesis in plants. In: Stacey, G. \& Keen, N.T. (Eds.). Plant Microbe Interactions, St. Paul, Minnesota. APD Press. 1999. pp.81-119.

BAKER, C.J. \& ORLANDI, E.W. Active oxygen in plant pathogenesis. Annual Review of Phytopathology 33:299-321. 1995.

BAKER, C.J., O’NEILL, N.R., KEPPLER, L.D. \& ORLANDI, E.W. Early responses during plant-bacterial interactions in tobacco cell suspensions. Phytopathology 81:1504-1507. 1991.

BALDRIDGE, C.W. \& GERARD, R.W. The extra respiration of phagocytosis. American Journal of Physiology 103:235-236. 1933. BREUSEGEM, F.V., VRANOVÁ, E., DAT, J.F. \& INZÉ, D. The role of active oxygen species in plant signal transduction. Plant Science 161:405-414. 2001.

DANGL, J.F., DIETRICH, R.A. \& THOMAS, H. Senescence and programmed cell death. In: Buchanan, B.B., Gruissem, W. \& Jones, R.L. (Eds.). Biochemistry and Molecular Biology of Plants. Rockville, Maryland. ASP Press. 2000. pp.1044-1101.

DIXON, R.A., HARRISON, M.J. \& LAMB, C.J. Early events in the activation of plant defense responses. Annual Review of Phytopathology 32:479-501. 1994.

DOKE, N. \& OHASHI, Y. Involvement of an $\mathrm{O}_{2}^{-}$generating system in the induction of necrotic lesions on tobacco leaves infected with tobacco mosaic virus. Physiological and Molecular Plant Pathology 32:163-175. 1988.

DOKE, N. Generation of superoxide anion by potato tuber protoplasts during the hypersensitive response to hyphal wall components of Phytophthora infestans and specific inhibition of the reaction by suppressors of hypersensitivity. Physiological Plant Pathology 23:359-367. 1983.

DOLLEDONNE, M., ZEIER, J., MAROCCO, A. \& LAMB, C. Signal interactins between nitric oxide and reactive oxygen intermediates in the plant hypersensitive disease resistance response. Proceedings of National Academic Science 98:1345413459. 2001.

FODOR, J., HIDEG, E., KEESKES, A. \& KYRALY, Z. In vivo detection of tobacco mosaic virus-induced local and systemic oxidative burst by electron paramagnetic resonance spectroscopy. Plant Cell Physiology 42:775-779. 2001.

FOYER, C.H., LELANDAIA, M. \& KUNERT, K.J. Photooxidative stress in plants. Physiologia Plantarum 92:696-717. 1994.

GARRE, V., TENBERGE, K.B. \& EISING, R. Secretion of a fungal extracellular catalase by Claviceps purpurea during infection of rye: putative role in pathogenicity and suppression of host defense. Phytopathology 88:744-753. 1998.

GOODMAN, R.N. \& NOVACKY, A.J. The hypersensitive reaction in plants to pathogens - a resistance phenomenon. St. Paul, Minnesota. APS Press. 1994.

HALLIWELL, B. \& GUTTERIDGE, J.M.C. Free radicals in biology and medicine. Oxford, University Press. 1989.

HAMMOND-KOSACK, K.E. \& JONES, J.D.G. Resistance genedependent plant defense responses. Plant Cell 8:1773-1791. 1996.

HAMMOND-KOSACK, K.E. \& JONES, J.D.G. Responses to plant pathogens. In: Buchanan, B.B., Gruissem, W. \& Jones, R.L. (Eds.) Biochemistry and Molecular Biology of Plants., Rockville, Maryland. 
M.L.V. Resende et al.

ASP Press. 2000. pp.1102-1156.

HEGEDUS, A., ERDEI, S. \& HORVÁTH, G. Comparative studies of $\mathrm{H}_{2} \mathrm{O}_{2}$ detoxifying enzymes in green and greening barley seedlings under cadmium stress. Plant Science 160:1085-1093. 2001.

KEPPLER, L.D. \& BAKER, C.L. O- initiated lipid peroxidation in a bacteria-induced hypersensitive reaction in tobacco cell suspensions. Phytopathology 79:555-562. 1989.

KEPPLER, L.D., BAKER, C.L. \& ATKINSON, M.M. .Active oxygen production during bacteria-induced hypersensitive reaction in tobacco suspension cells. Phytopathology 79:974-978. 1989.

LAMB, C. \& DIXON, R.A. The oxidative burst in plant disease resistance. Annual Review of Plant Physiology and Plant Molecular Biology 48:251-75. 1997.

MARTINEZ, C., BACCOU, J.C., BRESSON, E., BAISSAC, Y., DANIEL, J. F., JALLOUL, A., MONTILLET, J.L., GEIGER, J.P., ASSIGBETSE, K. \& NICOLE, M. Salicylic acid mediated by the oxidative burst is a key molecule in local and systemic responses of cotton challenged by an avirulent race of Xanthomonas campestris pv. malvacearum. Plant Physiology 122:757-766. 2000.

MEDHY, M.C., SHARMA, Y.K., SATHASIVAN, K. \& BAYS, N.W. The role of activated oxygen species in plant disease resistance. Physiologia Plantarum 98:365-374. 1996.

MOLLER, I.M. Plant mitochondria and oxidative stress: electron transport, NADPH turnover, and metabolism of reactive oxygen species. Annual Review Plant Physiology and Plant Molecular
Biology 52:561-91. 2001.

PENG, M. \& KUC, J. Peroxidase-generated hydrogen peroxide as a source of antifungal activity in vitro and on tobacco leaf discs. Phytopathology 82:696-699. 1992.

RODRÍGUEZ, A.A., GRUNBERG, K.A. \& TALEISNIK, E.L. Reactive oxygen species in the elongation zone of maize leaves are necessary for leaf extension. Plant Physiology 129:1627-1632. 2002.

STASKAWICZ, B.J., AUSUBEL, F.M., BAKER, B.J., ELLIS, J.G. \& JONES, J.D.G. Molecular genetics of plant disease resistance. Science 268:661-67. 1995.

SUTHERLAND, M.W. The generation of oxygen radicals during host plant responses to infection. Physiological and Molecular Plant Pathology 39:79-93. 1991.

WOHLGEMUTH, H., MITTELSTRASS, K., KSCHIESCHAN, S., BENDER, J., WEIGEL, H.J., OVERMYER, K., KANGASJARVI, J., SANDERMANN, H. \& LANGEBARTELS, C. Activation of an oxidative burst is a general feature of sensitive plants exposed to the air pollutant. Plant Cell \& Environment 25:717-723. 2002.

WU, G., SHORTT, V.J., LAWRENCE, E.G., LEVINE, E.B., FITZSIMMONS, K.C. \& SHAH, D.M. Disease resistance conferred by expression of a gene encoding $\mathrm{H}_{2} \mathrm{O}_{2}$ - generating glucose oxidase in transgenic potato plants. Plant Cell 7:1357-1368. 1995.

YOSHIMURA, K., YABUTA, Y., ISHIKAWA, T. \& SHIGEOKA, $\mathrm{S}$. Expression of spinach ascorbate peroxidase isoenzimes in response to oxidative stresses. Plant Physiology 123:223-233. 2000. 